\title{
Introspecting About Reasons Can Reduce Post-Choice Satisfaction
}

\author{
Timothy D. Wilson \\ Douglas J. Lisle \\ University of Virginia \\ Jonathan W. Schooler \\ University of Pittsburgh \\ Sara D. Hodges \\ Kristen J. Klaaren \\ Suzanne J. LaFleur \\ University of Virginia
}

This study tested the prediction that introspecting about the reasons for one's preferences would reduce satisfaction with a consumer choice. Subjects evaluated two types of posters and then chose one to take home. Those instructed to think about their reasons chose a different type of poster than control subjects and, when contacted 3 weeks later, were less satisfied with their choice. When people think about reasons, thy appear to focus on attributes of the stimulus that are easy to verbalize and seem like plausible reasons but may not be important causes of their initial evaluations. When these attributes imply a new evaluation of the stimulus, people change their attitudes and base their choices on these new attitudes. Over time, however, people's initial evaluation of the stimulus seems to return, and they come to regret choices based on the new attitudes.

He who deliberates lengthily will not aiways choose the best.

-Goethe

Introspection is often considered a uniquely human capability. Other species possess sophisticated cognitive and communicative skills (e.g., Premack \& Premack; 1983; Ristau \& Robbins, 1982), but as far as we know, we are the only species that thinks about its thoughts and feelings. Given the possibly unique status of our ability to self-reflect, it is tempting to view self-reflection as a uniformly beneficial activity. This assumption has been made, at least implicitly, by theorists in several areas of psychology. Many forms of psychotherapy view introspection as an integral part of the healing process, and some decision theorists argue that reflection about a choice will lead to better decision making (e.g., Janis \& Mann, 1977; Koriat, Lichtenstein, \& Fischhoff, 1980; Raiffa, 1968). Similarly, Langer $(1978,1989)$ has argued that we would be better off in most contexts if we were more "mindful" and contemplative about our actions.

Introspection and self-reflection undoubtedly can be very useful, with the ability to superimpose reason and discretion on otherwise impulsive actions. There is no reason to assume that introspection is always beneficial, however, and in fact, there may be times when it is best to avoid too much of it. There is a growing literature documenting the drawbacks of self-reflection and rumination. Morrow and Nolan-Hoeksema (1990) found that people who ruminated about a negative mood were less successful in improving their moods than people who performed a distracting task. Schooler and EngstlerSchooler (1990) found that people who verbalized their memories for nonverbal stimuli, such as faces, had an impaired memory for these stimuli, whereas Schooler, Ohlsson, and Brooks (1992) found that people who tried to verbalize solutions to insight problems performed more poorly than people who did not.

\footnotetext{
Authors' Note: This research was supported by National Institute of Mental Health Grant R01-MH41841. We would like to thank Annette Chiang and Coretta Organ for their expert assistance with the conduct of this research. We also thank Dan Lassiter for his valuable comments on a previous draft of this article. Address correspondence to Timothy D. Wilson, Department of Psychology, Gilmer Hall, University of Virginia, Charlottesville, VA 22903-2477.
}

PSPB, Vol. 19 No. 3, June $1993 \quad 331-339$

(c) 1993 by the Society for Personality and Social Psychology, Inc. 
We have been concerned with the possible harmful effects of a different kind of introspection-namely, thinking about the reasons for one's feelings. Thinking about reasons can be disruptive, we suggest, for the following reasons. People often have difficulty verbalizing exactly why they feel the way they do about an attitude object. The reasons that come to mind are ones that are accessible in memory and sound plausible, even if they are not completely accurate (Nisbett \& Wilson, 1977). For example, when looking at a painting by Monet, people might have a generally positive reaction. When thinking about why they feel the way they do, however, what comes to mind and is easiest to verbalize might be that some of the colors are not very pleasing and that the subject matter, a haystack, is rather boring. If so, people might adopt, at least temporarily, the more negative attitude implied by their reasons. We have found evidence in several studies for just this sequence of events. When people are asked why they feel the way they do about something, they often change their attitudes in the direction of the attitude implied by their reasons (for reviews, see Wilson, 1990; Wilson, Dunn, Kraft, \& Lisle, 1989; Wilson \& Hodges, 1992).

Even if people do not know exactly why they feel the way they do, it might seem that they would focus only on reasons that were consistent with their initial feelings. Why, for example, would people think of negative attributes of the Monet painting if their initial reaction were positive? As noted by Benjamin Franklin (1950), "So convenient a thing it is to be a reasonable creature, since it enables one to find or make a reason for every thing one has a mind to do." Undoubtedly such a justification process can and does occur. We simply suggest, that under some circumstances, the reasons that are most accessible and plausible do not correspond perfectly with people's initial affect, leading to attitude change. This is particularly likely to occur when people are not very knowledgeable about the attitude object, when their initial feelings and beliefs about the attitude object are inconsistent (Erber, Hodges, \& Wilson, in press; Millar \& Tesser, 1989), and when a contrary reason happens to be salient or accessible (Salancik, 1974; Seligman, Fazio, \& Zanna, 1980; for a more in-depth discussion of this issue, see Wilson, Dunn, et al., 1989; Wilson \& Schooler, 1991).

The fact that thinking about reasons can change people's attitudes does not demonstrate that it is in any way deleterious to reflect in this manner. In fact, it might even be argued that people's new attitudes are more informed and less impulsive and thus advantageous in some respects. We suggest, however, that the attitude change following introspection about reasons can have negative consequences. We assume that, left to their own devices, people often form satisfactory preferences and personal choices. People are certainly not perfect information processors, but they often manage to assign weights to the different attributes of alternatives that produce a satisfactory choice (satisfactory to them). People may not be aware of how they are weighting the information, but they often use schemes that are adaptive and functional. The old adage "I may not know why, but I know what I like" probably has more than a grain of truth to it.

If so, what happens when people introspect about why they feel the way they do? This kind of introspection, we suggest, can change an optimal weighting scheme into a less optimal one. When people analyze reasons, they might focus on those attributes of the attitude object that seem like plausible causes of their evaluations (e.g., the color of a painting) but were not weighted heavily before. Similarly, they might overlook attributes that were weighted heavily. As a result of this change in people's weighting scheme, they change their preferences. Assuming that their original preference was fairly optimal, this change in weights might lead to a less optimal preference.

We recently found support for this hypothesis in two studies (Wilson \& Schooler, 1991). In one, people who analyzed why they liked or disliked different brands of strawberry jam changed their preferences toward the jams. Consistent with our hypothesis that this change would be in a nonoptimal direction, their preferences corresponded less with expert ratings of the jams than the preferences of control subjects. In a second study, college students who analyzed why they felt the way they did about a series of courses they could take the following semester changed their minds about which courses to take, and these choices corresponded less with expert opinion (student evaluations of the courses) than the choices of control subjects did. These studies suggest that people who analyzed reasons changed their preferences in nonoptimal ways. The criterion of what constituted a "good" decision, however, is open to question. The fact that people's attitudes toward strawberry jams or college courses do not correspond to expert opinion does not mean that these attitudes are dysfunctional for those individuals. If the experts happen to prefer Brand $A$, but we prefer Brand B, what is the harm? As long as people themselves are happy with their preferences and choices, we have no grounds for criticizing these choices.

There is reason to believe, however, that people will be less satisfied with choices they make after thinking about why they feel the way they do. As we have seen, analyzing reasons can change the way people weight information about a stimulus, thereby changing their preferences. There is also evidence that these new preferences are not very stable, because they are contrary to the way people chronically evaluate stimuli in that do- 
main. We have found, for example, that the attitudes people express after analyzing reasons are poor predictors of their later behavior, behavior that occurs after people have had a chance to reevaluate the stimulus (see Wilson, Dunn, et al., 1989, for a review). One reason for this finding may be that when people analyze reasons, they change the way they weight information about the stimulus, but over time they return to their chronic weighting schemes, essentially reverting to their initial attitudes.

If so, people might come to regret choices that they make immediately after analyzing reasons. Consider the following example: A woman is looking for something to hang over her mantel and goes to a store that sells art posters. She is in a particularly introspective mood and decides to analyze why she feels the way she does about each poster she examines. After doing so, she decides which one she likes best, purchases it, and takes it home. There is a good possibility, we suggest, that the act of analyzing reasons will change this person's mind about which poster to purchase. Trying to verbalize her reasons may highlight features of the posters that were not central to her initial evaluations, leading to a change in her preferences. Put differently, this person is probably not fully aware of how she usually (i.e., chronically) forms evaluations of works of art, leaving her open to the kinds of attitude change we have found in our previous studies. But what will happen over the next few weeks, as she looks at the poster over her mantel? Our suspicion is that the features she focused on when she analyzed reasons would probably no longer be salient. Instead, she would revert to her chronic means of evaluating works of art, possibly causing her to regret her choice.

The present study tested the hypothesis that people who analyze reasons will change their preferences and consumer choices. We predicted that people who analyzed reasons for liking or disliking individual posters would become less happy with their choice of poster over time. We also explored whether the effects of analyzing reasons would be moderated by people's level of knowledge about art, as suggested by a study by Wilson, $\mathrm{Kraft}$, and Dunn (1989). Wilson, Kraft, and Dunn found that people who were unknowledgeable about politics changed their political attitudes after analyzing reasons whereas knowledgeable people did not. Unknowledgeable people were significantly more likely to bring to mind reasons that were evaluatively inconsistent, such that these reasons were more likely to imply an attitude different from their prior one. Knowledgeable people, in contrast, brought to mind reasons that were evaluatively consistent and more likely to reflect their prior attitude. In the present study, we examined whether people's knowledge about art had similar effects.
METHOD

\section{Subjects}

Forty-three female undergraduates at the University of Virginia volunteered for a study entitled "Posters" in return for course credit or a payment of $\$ 5$. We used only females because of their greater availability and to avoid sex differences in preferences for different kinds of posters. In previous studies on the effects of analyzing reasons on attitudes, we have not found sex differences.

\section{Materials}

Subjects evaluated five posters. Two had received high ratings in a pretest: paintings by Monet (Nymphéas) and Van Gogh (Les Iris Saint Rémy). The other three, which were much less popular in our pretesting, were of a more contemporary, humorous style: a cartoon of animals rising in a hot air balloon, a photograph of a cat perched on a rope with the caption "Gimme a Break," and a photograph of a cat standing at a fence with the caption "One Step at a Time." All the posters were mounted on cardboard and were either $18 \times 24$ in. or $20 \times 28$ in. $^{1}$

\section{Procedure}

Subjects, seen individually, were told that the purpose of the experiment was to examine the different kinds of visual effects that people like in pictures and drawings. The experimenter (who was unaware of the purpose of the study or the hypothesized results) explained that "what we're doing now is simply trying to gather some basic information that will help us in later studies." She seated the subject in a chair approximately $3 \mathrm{~m}$ from the posters, handed the subjects a questionnaire, and left the room.

Reasons analysis manipulation. Subjects were randomly chosen to receive one of two versions of this questionnaire. In the reasons condition, the questionnaire instructed subjects to describe why they liked or disliked each of the five posters, in order to organize their thoughts. They were told that they would not be asked to hand in their answers and were given half a page to describe their reasons for liking each poster. In the control condition, the questionnaire asked subjects for background information about their major and why they had chosen it, why they had decided to attend the University of Virginia, and their career plans.

\section{Dependent Measures}

Liking ratings. If subjects were in the reasons condition, the experimenter picked up their reasons questionnaire when she returned, mentioned that they would not be needing it anymore, and placed it in a trash can. Subjects in both conditions then rated how much they liked each poster on 9-point scales $(1=$ dislike very much 
and $9=$ like very $m u(h)$. The experimenter left the room while subjects made these ratings, having instructed them to slide their completed questionnaires through a slot in a covered box to maintain anonymity.

Choice measure. When the experimenter returned, she said that the experiment was over, gave the subject her credit slip or money, and proceeded to give a mock debriefing, in which she repeated that the purpose of the experiment was to determine what makes people like certain visual effects more than others. She then said:

Before you go, I have a little surprise for you. The professor in change of this study always likes to give people who participate a little something extra for being in the experiment. This time, he was able to get copies of these posters from the manufacturer, so you get to choose whichever one you like the best to take home.

She then explained that she had to go get an explanation sheet (which subjects expected to receive) and would return shortly. She told the subject to pick out the poster she wanted from bins that contained several copies of each poster and then left the room. Subjects thus made their choices unobserved by the experimenter. All posters were rolled up so that only their reverse, blank sides were showing. Therefore, when the experimenter returned, she could not tell which one the subject had taken (this was determined later by a count of how many posters were left in each bin).

After subjects had made their choice, the experimenter said she had forgotten to give them one final questionnaire, which assessed subjects' educational background in art. (The first eight subjects did not receive this questionnaire.) Finally, they were asked not to tell anyone that they had received a poster as part of the study, because the posters might run out and not be available for future participants.

Post-choice liking measure At the end of the semester, a different experimenter (unaware of subjects' condition) called subjects and asked them five questions concerning their satisfaction with their choice of poster: whether they still had it (verified by asking subjects to look at the bottom of the poster and read to the experimenter the name of the manufacturer), whether they had hung it on a wall in their dorm or apartment, whether they planned to keep it when they left school for the summer, how much they now liked the poster on a 10-point scale, and how much money it would take (hypothetically) to buy the poster from them. We called subjects an average of 25 days after they had participated in the experiment (range $=15$ to 40 ). ${ }^{2}$ We obtained responses from 40 of the 43 subjects; we could not reach the remaining 3 . At the conclusion of the study, we mailed all subjects a written explanation of its true purpose.
RESULTS

\section{Reported Liking for the Posters}

As predicted, subjects who thought about their reasons reported different attitudes than control subjects. Consistent with our pretesting, subjects in the control condition liked the art posters considerably more than the humorous posters. In contrast, subjects whoanalyzed reasons liked the art posters less than control subjects and liked the humorous posters more (see means in Table 1). We tested these differences by entering subjects' mean rating of the art posters and their mean rating of the humorous posters into a 2 (Condition: control vs. reasons analysis) $\times 2$ (Poster Type: art vs. humorous) between-within analysis of variance. This analysis yielded a highly significant Condition $\times$ Poster Type interaction, $F(1,41)=7.44, p<.01$, reflecting the fact that subjects who analyzed reasons rated the art posters lower and the humorous posters higher. The main effect of poster type was also highly significant, $F(1$, $41)=12.99, p<.01$, reflecting the fact that, overall, subjects preferred the art posters to the humorous ones. The main effect of condition was not significant, $F(1$, $41)=1.17$, n.s., reflecting the fact that analyzing reasons did not cause an across-the-board increase or decrease in liking for the posters.

\section{Choice of Paster}

As predicted, people in the reasons condition were more likely to choose one of the humorous posters to take home than people in the control condition. Among control subjects, 20 of $21(95 \%)$ chose one of the art posters, whereas only $14(64 \%)$ of 22 reasons subjects chose an art poster, $\chi^{2}(2)=4.71, p<.05$. The percentage choosing each poster is displayed in Table $1 .^{3}$

\section{Post-choice satisfaction}

A factor analysis revealed that the post-choice satisfaction measures could be considered to be two separate variables: the three behavioral-type questions (whether people still had the poster, whether they had hung it, and whether they planned to keep it) and the two subjective questions (how much people said they liked their poster and their "asking price" if someone wanted to buy it, which we first transformed to a logarithmic scale to reduce the variance). Accordingly, we entered the mean of the three behavioral responses and the mean of the two subjective responses (after converting them to standard scores) into a 2 (Condition: reasons vs. control) $\times 2$ (Type of Measure: behavioral vs. subjective) betweenwithin ANOVA. As predicted, people in the control condition expressed greater satisfaction with their choice than people in the reasons condition (means $=.26$ and -.26 , averaging across the behavioral and subjective in- 
TABLE 1: Reported Liking for the Posters and Percentage Who Chose Each One

\begin{tabular}{|c|c|c|c|c|c|}
\hline \multirow[b]{2}{*}{ Variable and Condition } & \multicolumn{2}{|c|}{ Art Posters } & \multicolumn{3}{|c|}{ Humorous Pasters } \\
\hline & $A$ & $B$ & C & $D$ & $E$ \\
\hline \multicolumn{6}{|l|}{ Reported liking ${ }^{2}$} \\
\hline $\begin{array}{l}M \\
(S D)\end{array}$ & $\begin{array}{c}6.62 \\
(2.18)\end{array}$ & $\begin{array}{c}7.48 \\
(1.66)\end{array}$ & $\begin{array}{c}3.88 \\
(2.32)\end{array}$ & $\begin{array}{c}4.00 \\
(2.72)\end{array}$ & $\begin{array}{r}3.76 \\
(2.64)\end{array}$ \\
\hline \multicolumn{6}{|l|}{ Reasons } \\
\hline $\begin{array}{l}M \\
(S D)\end{array}$ & $\begin{array}{c}5.50 \\
(2.67)\end{array}$ & $\begin{array}{c}6.59 \\
(2.84)\end{array}$ & $\begin{array}{c}6.17 \\
(2.33)\end{array}$ & $\begin{array}{c}5.39 \\
(2.45)\end{array}$ & $\begin{array}{c}4.83 \\
(2.50)\end{array}$ \\
\hline \multicolumn{6}{|l|}{ Percentage choosing } \\
\hline Control & 33 & 62 & 0 & 0 & 5 \\
\hline Reasons & 23 & 41 & 9 & 18 & 9 \\
\hline
\end{tabular}

NOTE: Poster A was the Van Gogh, Poster B was the Monet, Poster C was the cartoon of the balloons, Poster D was the cat with the caption "Gimme a Break," and Poster E was the cat with the caption "One Step at a Time."

a. The liking ratings were made on 9-point scales, with $1=$ diskike very much and $9=$ bike vory much

dexes). The main effect of reasons condition was significant, $F(1,38)=5.32, p=.02$. The Condition $\times$ Type of Measure interaction did not approach significance, $F(1$, $38)<1$, indicating that the magnitude of this effect was not reliably different on the behavioral and the subjective indexes. (In subsequent analyses we therefore averaged across these indexes.)

In Table 2 we have broken down the means by both condition and the type of poster people chose. It should be noted that the people who were most dissatisfied with their choice were those who analyzed reasons and chose one of the humorous posters, though the Reasons $X$ Choice interaction was nonsignificant, $F(1,36)<1$. Analyses that include Choice as a factor are difficult to interpret, however, given that this factor is a subject selfselection variable and some of the resulting cell sizes are extremely small.

It might be argued that the reasons manipulation reduced post-choice satisfaction because it lowered people's liking for the posters during the experimental session and this reduced liking persisted for several weeks. Alternatively, we predicted that subjects would be happy with their choice when they made it but that over time their initial evaluation in the reasons condition would reassert itself, resulting in a change in their liking. The results were consistent with this latter interpretation. First, as already seen, the main effect of the reasons manipulation on people's ratings of the posters at the experimental session was not significant, indicating that the manipulation did not lower satisfaction with the posters at this time. Second, as seen in the top half of Table 2, people's prechoice ratings of the poster they subsequently selected were as high in the reasons condi-
TABLE 2: Pre-and Post-Choice Ratings of the Posters Chosen

\begin{tabular}{|c|c|c|c|c|}
\hline \multirow[b]{2}{*}{ Rating } & \multicolumn{2}{|c|}{ Art Poster } & \multicolumn{2}{|c|}{ Humorous Paster } \\
\hline & $\begin{array}{l}\text { Control } \\
\text { Condition }\end{array}$ & $\begin{array}{c}\text { Reasons } \\
\text { Condition }\end{array}$ & $\begin{array}{l}\text { Control } \\
\text { Condition }\end{array}$ & $\begin{array}{l}\text { Roasons } \\
\text { Condition }\end{array}$ \\
\hline \multicolumn{5}{|c|}{ Prechoice liking ${ }^{2}$} \\
\hline$n$ & 20 & 14 & 1 & 8 \\
\hline$M$ & 7.85 & 8.50 & 9.00 & 8.25 \\
\hline \multicolumn{5}{|c|}{ Postchoice satisfaction $^{\mathbf{b}}$} \\
\hline$n$ & 19 & 14 & 1 & 6 \\
\hline$M$ & .23 & -.10 & -.17 & -.45 \\
\hline Adjusted $M^{C}$ & .27 & -.11 & -.24 & -.42 \\
\hline
\end{tabular}

tion as in the control condition. In fact, collapsing across type of poster, subjects in the reasons condition rated the poster they chose slightly higher. Finally, to test further the prediction that the differences in post-choice satisfaction were not due to differences in prechoice liking, we repeated the analysis on the post-choice liking index after adjusting the means for prechoice liking (see the adjusted means in Table 2). The significant effect of reasons condition remained, $t(37)=2.80, p<.01$.

It might also be argued that analyzing reasons reduced people's confidence in their attitudes toward the posters. Thinking about reasons might have muddied the waters, reducing the extent to which people preferred any one poster to another. The reduction in post-choice satisfaction might have stemmed from this bunching together of subjects' preferences; that is, people may have given all the posters similar ratings initially, reducing their eventual satisfaction with the one they chose. To test this bunching hypothesis, we computed a range score for each subject by subtracting her lowest from her highest rating of the posters. The difference between conditions in the mean range was nonsignificant, $t=.94$. Wilson and Schooler (1991) also found that people who analyzed reasons did not have a lower range in their ratings than control subjects. Finally, we have found in several previous studies that people who analyze reasons do not have lower confidence in their preferences than control subjects (Wilson, Dunn, et al., 1989).

\section{Analyses of Subjects' Reasons}

A research assistant divided people's responses on the reasons questionnaire into individual reasons and then assigned these reasons to different categories of why people liked or disliked the posters. (Another assistant independently coded a random subset of subjects' questionnaires. He agreed with the first coder's division of 
the responses into reasons $94 \%$ of the time and agreed with her classifications into categories $83 \%$ of the time.) Subjects gave an average of 2.85 reasons for liking or disliking each poster. These reasons concerned the colors in the posters $(20 \%)$, other aspects of the poster content $(54 \%)$, affective reactions or memories triggered by the poster (e.g., "It conveys a feeling of calmness," "It is a pleasant poster," 22\%), and the artist who painted the picture or took the photograph (3\%).

We predicted that when people analyzed reasons, thoughts would come to mind that were inconsistent with their initial affective reactions to the posters. Consistent with this hypothesis, people gave a relatively large number of reasons for liking the humorous posters and relatively few for disliking them, $M s=1.95$ versus 0.92 , $t(21)=3.22, p<.005$. They gave about the same number of reasons for liking and disliking the art posters, $M \mathrm{~s}=$ 1.59 versus $1.20, t(21)<1$. Given the overwhelming preference for the art posters among control subjects, it is unlikely that these reasons are an accurate reflection of the factors causing subjects' initial evaluations of the posters. Instead, the attributes of the posters that were easiest to verbalize as reasons seem to have been at least partly inconsistent with people's initial reactions. Once people had verbalized these reasons, we predicted that they would adopt the attitude the reasons implied. To address this question, an assistant coded people's reasons according to the attitude toward the posters they implied. (One of the authors coded a subset of the reasons, and his ratings correlated .91 with the assistant's.) Consistent with our hypothesis, the average within-subject correlation between this liking-expressed-in-reasons index and subjects' subsequent liking ratings was very high, mean $r=.93, t(21)=10.74, p<.001$. The liking-expressedin-reasons index was also significantly correlated with people's choice of poster, $r=.58, t(21)=4.24, p<.001$.

\section{Moderating Effects of Knowledge About Art}

To see whether level of knowledge about art moderated the results, we performed a mediarr split on the number of art courses people had taken in high school and college. ${ }^{4}$ The data about art courses were unavailable for the first eight subjects, and therefore the analyses have reduced power. Nonetheless, the results were generally consistent with the prediction that analyzing reasons would have a greater effect on people who were unknowledgeable about art. On people's initial ratings of the posters, the interaction among reasons condition, poster type, and knowledge was marginally significant, $F(1,31)=2.89, p=.10$. As expected, those who were low in knowledge showed the same Condition $\times$ Poster Type interaction discussed above, $F(1,31)=7.61, p=.01$. (That is, those who analyzed reasons liked the humorous posters more and the art posters less than control subjects;
TABLE 3: Initial Liking for the Posters by Level of Knowiedge

\begin{tabular}{|c|c|c|c|c|}
\hline \multirow[b]{3}{*}{ Type of Paster } & \multicolumn{4}{|c|}{ Lovel of Knowledge } \\
\hline & \multicolumn{2}{|c|}{ Low } & \multicolumn{2}{|c|}{ High } \\
\hline & $\begin{array}{c}\text { Control } \\
\text { Condition }\end{array}$ & $\begin{array}{l}\text { Roasons } \\
\text { Condition }\end{array}$ & $\begin{array}{l}\text { Control } \\
\text { Condition }\end{array}$ & $\begin{array}{l}\text { Reasons } \\
\text { Condition }\end{array}$ \\
\hline Art & 7.39 & 5.56 & 6.25 & 6.50 \\
\hline Humorous & 3.63 & 6.08 & 4.17 & 4.97 \\
\hline
\end{tabular}

NOTE: The liking ratings were made on 9-point scales, with $1=$ diskike vary much and $9=$ bike very much.

see Table 3.) This interaction was not significant among people high in knowledge, $F(1,31)<1$. Knowledge did not moderate the effects of analyzing reasons on people's choice of poster, $F(1,31)<1$, possibly because this dichotomous dependent measure was of low power.

On the measure of post-choice satisfaction, the effects of the reasons manipulation were most pronounced among unknowledgeable people, $M \mathrm{~s}=.21$ and -.54 in the control and reasons conditions, respectively. Among people high in knowledge, these means were .14 and -.02. Although the Reasons Condition $\times$ Knowledge interaction was not significant, $F(1,29)=2.33, p=.14$, a contrast testing the predicted pattern of results was significant, $F(1,29)=8.62, p<.01$ (this contrast assigned a weight of -3 to the low knowledge/reasons cell and +1 to the other three cells).

Wilson, Kraft, and Dunn (1989) found that when unknowledgeable people analyzed reasons, they were more likely to call to mind a poorly articulated, inconsistent set of beliefs, such that at least some of these reasons were inconsistent with their prior attitude, leading to attitude change. Knowledgeable people, in contrast, called to mind a consistent set of beliefs that better reflected their prior attitude and were less likely to change their attitudes after analyzing reasons. To see whether a similar process occurred in the present study, we computed the same index of evaluative consistency used by Wilson, Kraft, and Dunn (1989). We divided the number of reasons for tiking or disliking the posters (whichever was greater) by the total number of reasons people gave, such that the higher this ratio, the more evaluatively consistent the reasons (e.g., if someone gave all negative or all positive reasons, she received a score of 1$)$. Given that our measure of knowledge was people's formal educational experience with art, we expected subjects to differ primarily in their thoughts about the art posters (i.e., there is no reason to expect that taking art courses gives people any more expertise in the genre of humorous posters). Consistent with this reasoning, knowledgeable people showed more evaluative consistency in their reasons about the art posters than control subjects ( $M s=.80$ and .65 , respectively) but did not show 
any more consistency in their reasons about the humorous posters ( $M s=.71$ and .73 , respectively). A Knowledge $\times$ Poster Type ANOVA on the measure of evaluative consistency revealed a nearly significant interaction, $F(1$, 16) $=3.62, p=.08$.

\section{DISCUSSION}

The present findings add to the mounting body of evidence that thinking about the reasons for one's preferences can alter decision making in nonoptimal ways. Subjects instructed to think about the reasons for their attitudes were more likely to prefer the humorous posters than control subjects and were more likely to choose a humorous poster to take home. After a few weeks had elapsed, however, they were less satisfied with their choice. Consistent with previous findings, these effects were especially pronounced among people who were relatively unknowledgeable about art.

Apparently the qualities of the art posters that made them appealing to our subject population were relatively difficult to verbalize, whereas positive features of the humorous posters were easy to verbalize, producing a biased sample of reasons. Consistent with this hypothesis, when people analyzed reasons, they verbalized more positive features of the humorous than the art posters and more negative features of the art than the humorous posters. Verbalizing these reasons caused subjects to adopt the attitude they implied, as suggested by the high correlation between the liking-expressed-in-reasons index and subsequent ratings of the posters and by the fact that reasons subjects chose different posters to take home.

We suggest that, over time, people's initial evaluations returned, causing those who analyzed reasons to regret their choice. Once these participants took the poster home, it is unlikely that they continued to analyze reasons every time they looked at it. Consequently, the reasons which were salient at the time they chose the poster-and which appear to have driven their choiceprobably faded in memory, and their chronic way of evaluating posters probably returned. We know from the control condition that when people in our subject population do not analyze reasons, they do not particularly like the humorous posters. Therefore, if people in the reasons condition became more like control subjects, in that they no longer analyzed reasons, we would expect them to become dissatisfied with their choice.

This explanation, we should note, is consistent with our prior work showing that analyzing reasons reduces attitude-behavior consistency. As noted by Wilson, Dunn, et al. (1989), this reduction in consistency is particularly likely if some interval separates the measure of people's attitude and the measure of their behavior. With such a separation, people's attitudes are likely to be driven by the newly salient information resulting from analyzing reasons, whereas their behavior is likely to be driven by their chronic way of evaluating the stimulus. Similarly, in the present study, people's choice of poster was driven by the reasons they had just brought to mind, but their attitudes several weeks later were probably driven more by their chronic way of evaluating posters.

According to this interpretation, the people who should have been the least happy with their choice are those for whom the reasons manipulation was particularly effective-namely, those in the reasons condition who chose a humorous poster. If the reasons manipulation did not change people's choices, such that they still chose an art poster, there is no reason to assume that they would be unhappy with this choice. The results shown in Table 2 are consistent with this line of reasoning, in that postchoice satisfaction was lowest among people in the reasons condition who chose a humorous poster. We acknowledge, however, that it is difficult to test this hypothesis, because it relies on a subject self-selection variable—which poster people chose. Further, including the poster people chose as a factor in the analyses results in extremely small cell sizes (in one case, a cell $\boldsymbol{n}$ of 1-see Table 2).

We should emphasize that subject self-selection was not a problem in our primary test of the effects of analyzing reasons on post-choice satisfaction: Those who analyzed reasons were significantly less satisfied, collapsing across their choice of poster. The more fine-grained prediction that people who analyzed reasons and chose a humorous poster would be the least satisfied cannot be addressed definitively, because the relevant findings, though in the predicted direction, are contaminated by self-selection. Thus, the results are consistent with the prediction that analyzing reasons changed people's attitudes temporarily and that their chronic way of evaluating the posters returned, but this explanation needs to be verified more directly by future research.

The fact that analyzing reasons led to a decrease in postchoice satisfaction is particularly impressive in light of the considerable amount of research generated by dissonance theory on postdecisional satisfaction. This research shows that once people make a choice, their liking for the chosen alternative increases, in order to reduce the psychological tension created by the knowledge that they could have chosen other, attractive alternatives (e.g., Brehm, 1956). Despite these internal pressures to like what they chose, subjects who analyzed reasons became more dissatisfied with their choice than control subjects. Our findings are not inconsistent with dissonance research; were it not for pressures to reduce dissonance, subjects in the reasons conditions might have been even more displeased with their choices. The 
results do suggest, however, that there are limits to the extent to which people can convince themselves that what they chose was the best alternative.

These results, in conjunction with several other recent studies, illustrate that introspection can have unintended negative consequences (Wilson \& LaFleur, 1993; Wilson \& Schooler, 1991). We cannot emphasize too strongly, however, that we are not making a broadsided attack on introspection and self-reflection. Such an attack is unwarranted for several reasons. First, some affective reactions are very unpleasant, either to the individual experiencing them (e.g., speech anxiety) or to the target of the affect (e.g., racial prejudice). It would be beneficial to alter these reactions, even if only temporarily, by having people examine the reasons that underlie them (Tesser, Leone, \& Clary, 1978).

Second, there is evidence that other kinds of selfreflection, such as focusing on one's feelings (without attempting to explain the reasons for them), does not disrupt people's attitudes in the way that analyzing reasons does (Miliar \& Tesser, 1986; Wilson \& Dunn, 1986). Simply focusing on a feeling can strengthen it, whereas recruiting reasons that may not be consistent with one's initial affective reaction can lead to attitude change (see Wilson, Dunn, et al., 1989).

Third, we have examined introspection in a limited set of circumstances. For example, people introspected for a fairly short time in our studies, and it is possible that a more lengthy, in-depth analysis would not have had the same negative consequences (although in a recent study we found that asking people to analyze reasons four times on separate occasions resulted in about the same amount of attitude change as did analyzing reasons only once; Wilson \& $\mathrm{Kraft}$ in press).

Fourth, for analyzing reasons to have negative effects, the reasons that are accessible and plausible to people must conflict with their initial affect. In the present study, the reasons that were most salient-such as the pleasingness of the colors of the posters-happened to conflict with people's initial attitudes. Some stimuli may have a more limited range of plausible reasons, so that people are unlikely to be misled by analyzing these reasons. Attitudes toward a can opener, for example, are probably relatively easy to explain. The pool of plausible reasons for liking a can opener is small, and these reasons probably correspond fairly well to the real reasons people like can openers. Even with more complex stimuli, people will not be misled if the reasons that come to mind match their initial affect-even if those reasons are wrong. For example, if people like a painting, and the most accessible reason for their feelings is that it has nice colors (i.e., a positive reason), they will not change their attitudes toward it, even if the colors had nothing to do with their initial evaluation.
When will people bring to mind reasons that conflict with an initial attitude? Because knowledgeable people have more consistent beliefs, they appear to be less likely to bring to mind reasons that conflict with their prior evaluation of the attitude object. That is, if people have homogeneous beliefs about an attitude object, all of which imply the same attitude, then focusing on a subset of these beliefs when analyzing reasons will not cause attitude change. Unknowledgeable people appear to have a less consistent set of beliefs, increasing the likelihood that when they analyze reasons, thoughts will come to mind that conflict with their prior attitude. Consistent with this view, unknowledgeable people in both the present study and Wilson, Kraft, and Dunn's (1989) expressed reasons that were less evaluatively consistent, and changed their attitudes more, than knowledgeable people (see also Lusk \& Judd, 1988). Further, Wilson, Kraft, and Dunn (1989) found that unknowledgeable people were more likely to bring to mind reasons that conflicted with their prior attitude (prior attitudes were not assessed in the present study).

Clearly more work is needed to specify the conditions under which introspecting about reasons will have deleterious consequences. The present study suggests, however, that unbridled claims about the value of introspection need to be tempered. Janis and Mann (19.77), for example, suggested that decisions should always be made analytically and vigilantly and that if they are not, people will be most likely to "undergo unanticipated setbacks and experience postdecisional regret" (p.11). In contrast, our findings suggest that it is not always advantageous to make decisions vigilantly and that, under some circumstances, those who do will be the ones who experience the most regret. Introspection is undoubtedly a valuable, useful ability, but as with most good things, there are times when it is best done in moderation.

\section{NOTES}

1. The first four subjects in each condition saw a different set of humorous posters: a drawing of penguins, a drawing of hot air balloons, and a photograph of a cat with a different caption. Because these posters were discontinued by the manufacturer, we switched to the humorous posters described in the text for the remaining subjects. The two art posters were identical for all subjects. Liking ratings reported for the humorous posters include only those subjects who saw the second set of posters.

2. These figures do not include the first four subjects in each condition. They were run at the end of the previous semester, and so considerably more time elapsed before they were called ( $M=188$ days). The results of our postchoice satisfaction measure remain significant, with nearly identical plevels, when these subjects are removed from the analyses.

3. The average within-subject correlation between people's liking ratings and choice of poster was .60 , which differed significantly from zero, $t(42)=11.53, p<.001$. This cor relation did not differ significantly by condition, $t(41)=1.07$, n.s. This result is consistent with our hypothesis that if people act on their attitudes soon after analyzing reasons, their behavior will be consistent with the new attitude that the 
reasons analysis produced. If behavior is measured at a later point in time, so that people have had a chance to reevaluate the stimulus, then their behavior is likely to be less consistent with the attitude produced by the reasons analysis. See Wilson, Dunn, Kraft, and Lisle (1989) for a more complete discussion of this issue and for more evidence bearing on it.

4. Strictly speaking, we measured people's educational experience with art, not their level of knowledge. We use the term knowledge to be consistent with previous studies that assessed it with measures of experience (e.g., Wilson, Kraft, \& Dunn, 1989; Wood, 1982) and because experience has been found to correlate significantly with knowledge (Davidson, Yantis, Norwood, \& Montano, 1985).

\section{REFERENCES}

Brehm, J. W. (1956). Post-decision changes in desirability of alternatives. Joumal of Abromal and Social Psychology, 52, 384-389.

Davidson, A. R, Yantis, S., Norwood, M., \& Montano, D. E (1985). Amount of information about the attitude object and attitude-behavior consistency. Joumal of Parsonatily and Social Psychology, 49, $1184-1198$.

Erber, M. W., Hodges, S. D., \& Wilson, T. D. (in press). Attitude strength and attitude stability. In R E. Petry \& J. A. Krosnick (Eds.), Attitude strength: Antecedents and consequence. Hilisdale, NJ: Lawrence Erlbaum.

Franklin, B. (1950). The auliobiogrophy of Benjamin Franklin New York: Pocket Books.

Janis, I. L. \& Mann, L. (1977). Decision making: A psychological anabysis of conflich choice and commitment New York: Free Press.

Koriat, A., Lichtenstein, S., \& Fischhoff, B. (1980). Reasons for confidence. Joumal of Experimental Psychology: Human Learning and Mem ory, 6, 107-118.

Langer, E J. (1978). Rethinking the role of thought in social interaction. In J. H. Harvey, W. J. 1ckes, \& R. F. Kidd (Eds.), Naw directions in altribution research (Vol. 2, Pp. 35-58). Hillsdale, NJ: Lawrence Eribaum.

Langer, E. J. (1989). Minding matters: The consequences of mindlessness-mindfulness. In L Berkowitz (Ed.), Advances in experimental social psychology (Vol. 22, pp. 137-173). San Diego, CA: Academic Press.

Lusk, C M., \& Judd, C. M. (1988). Political expertise and the structural mediators of candidate evaluations. Joumal of Exparimental Social Psychology, 24, 105-126.

Millar, M. G., \& Tesser, A (1986). Effects of affective and cognitive focus on the attitude-behavior relationship. Joumal of Personality and Social Psychology, 51, 270-276.

Millar, M. G., \&e Tesser, A. (1989). The effects of affective-cognitive consistency and thought on the autude-behavior relation. Journal of Experimental Social Psychology, 25, 189-202.

Morrow, J., \& Nolan-Hoeksema, S. (1990). Effects of responses to depression on the remediation of depressive affect. Joumal of Personatity and Social Psychology, 58, 519-527.

Nisbett, R. E, \& Wilson, T. D. (1977). Telling more than we can know. Verbal reports on mental processes. Psychological Review, 84, 231-259.
Premack, D., \& Premack, A. J. (1983). The mind of an ope New York: Norton.

Raiffa, H. (1968). Decision anabysis. Reading, MA: Addison-Wesley.

Ristau, C. A., \& Robbins, D. (1982). Language in the great apes: A critical review. In J. S. Rosenblatt, R A. Hinde, C Beer, \& M. Busnel (Eds.), Advances in the study of behavior (Vol. 12, pp. 141-255). New York: Academic Press.

Salancik, G. R. (1974). Inference of one's attitude from behavior recalled under linguistically manipulated cognitive sets. Joumal of Experimental Social Psychology, 10, 415-427.

Schooler, J. W., \& Engstier-Schooler, T. Y. (1990). Verbal overshadowing of visual memories: Some things are better left unsaid. Cognitive Pyychology, 22, 36-71.

Schooler, J. W., Ohisson, S., \& Brooks, K. (1992). Thoughts boyond words: When languags overshadows insight. Unpublished manuscript, University of Pittsburgh.

Seligman, C., Fazio, R. H., \& Zanna, M. P. (1980). Effects of salience of extrinsic rewards on liking and loving. Joumal of Personality and Social Psychology, 38, 453-460.

Tesser, A., Leone, C., \& Clary, G. (1978). Affect control: Process constrain ts versus catharsis. Cogritive Therapy and Research, 2, 265-274.

Wilson, T. D. (1990). Self-persuasion via self-reflection. In J. M. Olson \& M. P. Zanna (Eds.), Self-inference processes: The Ontario Symposizem (Vol. 6, pp. 43-67). Hillisdale, NJ: Lawrence Eribaum.

Wilson, T. D., \& Dunn, D. S. (1986). Effects of introspection on attimde-behavior consistency: Analyzing reasons versus focusing on feelings. Journal of Experimental Social Psychology, 22, 249-263.

Wilson, T. D., Dunn, D. S., Kraft, D., \& Lisle, D. J. (1989). Introspection, attiude change, and attiude-behavior consistency. The distuptive effects of explaining why we feel the way we do. In L Berkowitz (Ed.), Advances in experimental social psychology (Vol. 22, pp. 287-343). San Diego, CA: Academic Press.

Wilson, T. D., \& Hodges, S. D. (1992). Attitudes as temporary constructions. In A. Tesser \& L Martin (Eds.), The construction of social judgment (pp. 37-65). Hillsdale, NJ: Lawrence Erlbaum.

Wilson, T. D., \& Kraft, D. (in press). Why do I love thee? Effects of repeated introspections about a dating relationship on attitudes toward the relationship. Personality and Social Psychology Bulletin.

Wilson, T. D., Kraft, D., \& Dunn, D. S. (1989). The disruptive effects of explaining attitudes: The moderating effect of knowledge about the attiude object. Joumal of Experimental Social Pyychology, 25, 379-400.

Wilson, T. D., \& LaFleur, S. J. (1993). [Effects of analyzing reasons on the accuracy of self-predictions]. Unpublished data, University of Virginia.

Wilson, T. D., \& Schooler, J. (1991). Thinking too much: Introspection can reduce the quality of preferences and decision. Joumal of Pessonality and Social Pyychology, 60, 181-192.

Wood, W. (1982). Retrieval of attitude-relevant information from memory: Effects on susceptibility to persuasion and on intrinsic motivation. Joumal of Personality and Social Psychology, 42, 798-810.

Received January 31, 1992

Revision received August 20, 1992

Accepted August 20, 1992 